\title{
CUNHA, Célio da; SOUZA, José Vieira; SILVA, Maria Abádia da (Orgs.). Diversidade metodológica na pesquisa em educação. Coleção Políticas Públicas em Educação. Campinas: Autores Associados, 2013. 320 p.
}

\author{
Jauri dos Santos Sá* \\ Maria Tereza Cauduro*
}

A coletânea Diversidade metodológica na pesquisa em educação apresenta artigos da linha de pesquisa Políticas Públicas e Gestão da Educação do Programa de Pós-Graduação em Educação da Universidade de Brasilia (PPGE/UnB), no período de 2011 a 2013. A coleção apresenta pesquisas de doutorandos e mestrandos, nas perspectivas do materialismo histórico-dialético e da fenomenologia, nos tipos bibliográfica, colaborativa, exploratória, historiográfica, estudo de caso e estudos de casos múltiplos, selecionadas por Célio da Cunha, José Vieira de Souza e Maria Abádia da Silva. O primeiro é doutor em Educação pela Unicamp e professor do programa de mestrado e doutorado da Universidade Católica de Brasília, o segundo é doutor em Sociologia pela UnB e professor na mesma universidade e a terceira é doutora em Educação pela Unicamp e professora na UnB.

Embora discutam temáticas das várias linhas de pesquisa do programa, os textos têm como marca identitária a explicitação da abordagem metodológica que os orientou. Os artigos abrangem temas sobre ensino superior, trabalho docente e aprendizagem e subjetividade. A organização dos trabalhos permitiu constituir um sumário dividido em três partes abrangendo as produções acadêmicas que oportunizaram uma clara discussão metodológica articulada à dimensão teórica.

A primeira parte - Avaliação e qualidade na educação superior -, composta por três artigos, é reservada a duas dissertações de mestrado e mais um trabalho de natureza bibliográfica, o único que não decorre de tese ou dissertação.

O primeiro artigo intitula-se Sentido e Significados do Índice Geral de Cursos na regulação da qualidade da educação superior. Trata-se de uma pesquisa com abordagem dialética, perspectiva do materialismo histórico - dialético, evidenciando os passos percorridos na investigação com quatro instituições do Distrito Federal.

\footnotetext{
*Desenvolve estágio pós-doutoral no Programa de Pós-Graduação da Universidade do Vale do Rio dos Sinos (Unisinos), E-mail: <arqjauri@gmail.com>

** Pesquisadora convidada do Programa de Pós-Graduação em Educação da Universidade do Vale do Rio dos Sinos.E-mail: <maitecauduro@gmail.com>.
} 
A pesquisa parte da premissa de que a compreensão dos fenômenos em sua totalidade deve respaldar-se na relação que se estabelece entre as singularidades, particularidade e universalidade. No artigo é possível visualizar o objeto de pesquisa, a explicitação de conceitos, seu método exploratório com abordagem "quali-quantitativa", objetivos do estudo e a escolha do contexto investigado. Expõe a pesquisa detalhando didaticamente como foi construída assim como apresenta seus resultados mesclando com um breve histórico da Avaliação no País, o Índice Geral de Cursos, o ENADE, relacionando comparativamente as quatro instituições investigadas.

Conceito cinco no ENADE em cursos de pedagogia: percepções de gestores, professores $e$ alunos versa sobre uma pesquisa de abordagem fenomenológica com duas instituições do Nordeste. Teve como objetivo "investigar as percepções de gestores, professores e alunos em cursos de pedagogia acerca do referido exame e as razões atribuídas por eles ao conceito cinco, obtido no ENADE de 2008." (p.47). Explicita o caminho metodológico fundamentado nas ideias de Husserl e os teóricos que dão suporte, conceituando o método e o tipo de pesquisa: estudo de caso. Expõe o objetivo da pesquisa, seu foco e o contexto do ENADE. Didaticamente apresenta os instrumentos de coleta de dados, as unidades de significado e a construção da análise em três grandes unidades: O ENADE na perspectiva da avaliação formativa; o ENADE e a relação com a qualidade; críticas ao ENADE (p.55). Descreve, na análise, a construção detalhada entre as evidências dos entrevistados e os autores proeminentes que respaldam a avaliação.

Diferentes vozes sobre a epistemologia avaliativa subjacente ao ENADE como componente dos SINAES é o único texto do livro que não se trata de dissertação ou tese produzida no PPGE/UnB, embora as coautoras sejam duas doutorandas do programa. De natureza bibliográfica, a pesquisa se apresenta a partir de um conjunto de 22 obras do Scientific Electronic Library Online (Scielo), levantadas no período de 2006 a 2012. A análise deu-se na perspectiva do materialismo histórico-dialético, refletindo sobre os contextos históricos nas tensões entre o Estado e a academia em relação à avaliação da educação superior no Brasil e discute as contradições encontradas em análises acadêmicas sobre a epistemologia avaliativa (formativa ou somativa) subjacente ao ENADE. O debate produzido no texto partiu de dois pressupostos: primeiro, que as discussões sobre a natureza e a finalidade do processo de avaliação da educação superior têm produzido tensões que traduzem interesses de diferentes atores e grupo de atores inseridos em um campo de grande heterogeneidade institucional; segundo, que o ENADE é o componente do SINAES que tem ganhado mais centralidade nos últimos anos na mensuração da qualidade da educação superior no país.

Na segunda parte - História, formação e trabalho docente - , três artigos oriundos de dissertações de mestrado privilegiam: (a) a história profissional dos 
professores pioneiros no Distrito Federal; (b) o espaço da coordenação pedagógica como local de formação e desenvolvimento docente; e (c) os fenômenos históricos nos quais se inserem as perspectivas de trabalho docente.

O primeiro artigo História da profissão docente: as narrativas das professoras pioneiras nos oferece uma contribuição à história da profissão docente no Distrito Federal, através do testemunho das próprias protagonistas, suas narrativas e experiências, individuais e coletivas. A investigação realizada pelo autor foi subsidiada pela teoria da sociologia das profissões, com o intuito de visualizar a história da profissão a partir da abordagem sociológica. Desenvolvido mediante uma pesquisa historiográfica, o traçado metodológico foi concebido com base na história nova. O tempo, a memória, os escritos e o dito constituíram-se em um cenário para recompor a trajetória profissional dos professores pioneiros. Ao inquirir como emergem as profissões, como se constituem, ou que relações estabelecem no nível macrossocial e microssocial, o autor reflexiona sobre "o sentido e significado que as professoras pioneiras deram ao seu próprio trabalho, [...] destacando a figura do professor pioneiro como peça fundamental na vida da nascente sociedade brasiliense" (p. 160).

A coordenação pedagógica como cenário de formação e desenvolvimento profissional docente discute a formação continuada dos professores como um importante elemento do processo de desenvolvimento profissional. Para aprofundar o tema, os autores optaram por uma abordagem fenomenológica de pesquisa qualitativa, atuando como orientadores dos estudos e das discussões propostas, além de investigadores das questões apresentadas, a fim de promover uma relação de trocas por meio de atividades reflexivas nos momentos de estudo e debates. Para fazer emergir informações, os autores utilizaram alguns instrumentos como: a entrevista individual, discussão em grupo ou entrevista coletiva, ou as ações reflexivas. A pesquisa teve como sujeitos quatro professores de matemática do Ensino Fundamental dos anos finais de duas escolas de Brasília. Os resultados obtidos revelaram "a importância de se pensar na realização frequente de pesquisa de cunho colaborativo, em que professores e pesquisador trabalham e desenvolvem-se juntos, promovendo a aprendizagem, a mudança e, ainda, estreitando a relação entre escola e universidade." (p. 197).

Por fim, o texto Trabalho docente em tempos de neoliberalismo apresenta as questões sobre a concepção de trabalho docente e a função que o professor assume mediante um olhar crítico em relação ao atual estágio do capitalismo. A autora trabalhou com o método da pesquisa qualitativa e optou pelo estudo de caso como estratégia de investigação. Já o universo da pesquisa foi delimitado por dois critérios: o professor participante deveria estar atuando desde a publicação da LDBEN e dar aula nos anos finais do Ensino Fundamental. Para a coleta de informações utilizou entrevistas semiestruturadas, roteiro para observações e de fontes documentais primárias. 
A autora fez uma "análise mediante a perspectiva crítico-dialética, apoiando-se em Cury (2000) e Kuenzer (1998), intentando enxergar os fenômenos históricos por trás das perspectivas de trabalho docente dos professores" (p. 206).

Na última parte do livro - Subjetividade, inovação e aprendizagem - dois artigos, um oriundo de tese de doutorado e outro de dissertação de mestrado abordam: (a) a epistemologia qualitativa como alternativa capaz de mostrar as ferramentas metodológicas para investigar os processos subjetivos no ambiente escolar; (b) o processo de construção do diagnóstico de dificuldades de aprendizagem realizado pelo Serviço Especializado de Apoio à Aprendizagem da Secretaria de Estado de Educação do Distrito Federal.

Processos subjetivos e inovação educativa: um estudo de caso com base na epistemologia qualitativa deriva da tese de doutorado. Nesse artigo, as autoras optaram por abordar essencialmente o marco teórico, os princípios epistemológicos, as estratégias metodológicas, os resultados e as conclusões do estudo. Sobre a inovação, as autoras enfatizam que, embora presente em várias dimensões da vida humana, esse é um tema de estudo recente na educação, sendo frequentemente relacionado às praticas pedagógicas. A investigação realizada foi subsidiada pelo paradigma da complexidade e pela teoria histórico-cultural da subjetividade, as quais "oferecem o campo epistemológico e teórico que possibilita a aproximação da tentativa de compreender a inovação educativa como produção humana complexa no contexto das instituições educacionais." (p. 247). Apoiada em instrumentos e procedimentos de caráter aberto e construtivo, utilizaram os seguintes instrumentos: observação participante, análise documental, conversas informais e entrevistas selecionadas e instrumentos escritos.

Finaliza a áltima parte do livro o texto $O$ processo de construção do diagnóstico de dificuldade de aprendizagem e as concepcóes nele imbricadas. A autora buscou uma pesquisa de sustentação teórica baseada nos pressupostos da perspectiva histórico-cultural. Teve como objetivo "compreender o processo de construção do diagnóstico de dificuldade de aprendizagem realizado pelo SEAA da SEE$\mathrm{DF}$, a fim de perceber que concepções o permeiam e quais expectativas o cercam.” (p.291). A pesquisa foi qualitativa baseada em González Rey (2002) e seus três princípios epistemológicos: (a) o processo de investigação; (b) o caráter construtivo-interpretativo do conhecimento; (c) a legitimação do singular como instância de produção do conhecimento científico. Apresenta detalhadamente os conceitos teóricos que a sustentam, os instrumentos utilizados, os sujeitos colaboradores e as análises que foram realizadas com os princípios construtivointerpretativo. O diferencial desse processo foi a admissão do caráter ativo do pesquisador na construção teórica. Ao final do texto, expõe a análise detalhada de cada categoria e, ao finalizar cada uma, coloca as "concepções percebidas" e encaminhamentos aos investigados. 
O leitor interessado em aprofundar as questões metodológicas da pesquisa em Educação terá nessa coletânea textos que apontaram avanços e desafios, explicitando a dimensão metodológica de forma articulada à dimensão teórica, vital para pesquisas realizadas no campo educacional. Os mesmos darão suporte a mestrandos, doutorandos e a professores dos PPGs nas pesquisas qualitativas e quali-quantitativas. 